\title{
Estimating deaths attributable to airborne particles: sensitivity of the results to different exposure assessment approaches
}

\author{
Simone Giannini ${ }^{1,2^{*}}$, Michela Baccini ${ }^{3}$, Giorgia Randi ${ }^{4,5}$, Giovanni Bonafe ${ }^{6,7}$, Paolo Lauriola ${ }^{1}$ and Andrea Ranzi ${ }^{1}$
}

\begin{abstract}
Background: Epidemiological evidences support the existence of an effect of airborne particulate on population health. However, few studies evaluated the robustness of the results to different exposure assessment approaches. In this paper, we estimated short term effects and impacts of high levels of particulate matter with aerodynamic diameter $\leq 10 \mu \mathrm{m}\left(\mathrm{PM}_{10}\right)$ and $\leq 2.5 \mu \mathrm{m}\left(\mathrm{PM}_{2.5}\right)$ in the Emilia-Romagna region (Northern Italy), one of the most polluted areas in Europe, in the period 2006-2010, and checked if the results changed when different exposure definitions were used.

Methods: Short-term impact of particles on population mortality was assessed, both considering the 9 provincial capitals of the Emilia-Romagna and the region as a whole. We estimated the effects of $\mathrm{PM}_{10}$ and $\mathrm{PM}_{2.5}$ on natural mortality by combining city-specific results in a Bayesian random-effects meta-analysis, and we used these estimates to calculate impacts in terms of attributable deaths. For $\mathrm{PM}_{10}$, we considered different definitions of exposure, based on the use of the air pollutant levels measured by different monitoring stations (background or traffic monitors) or predicted by a dispersion model.
\end{abstract}

Results: Annual average concentrations of $\mathrm{PM}_{10}$ and $\mathrm{PM}_{2.5}$ exceeding the WHO limits of 20 and $10 \mu \mathrm{g} / \mathrm{m}^{3}$ were respectively responsible for 5.9 and 3.0 deaths per 100000 inhabitants per year in the provincial capitals, during the period 2006-2010. The total impact in the region in 2010 amounted to 4.4 and 2.8 deaths per 100000 for $\mathrm{PM}_{10}$ and $\mathrm{PM}_{2.5}$, respectively. The impact estimates for $\mathrm{PM}_{10}$ did not substantially change when the exposure levels were derived from background or traffic monitoring stations, or arose from the dispersion model, in particular when the counterfactual value of $20 \mathrm{\mu g} / \mathrm{m}^{3}$ was considered. The effect estimates appeared more sensitive to the exposure definition.

Conclusions: A reduction in particle concentrations could have produced significant health benefits in the region. This general conclusion did not change when different exposure definitions were used, provided that the same exposure assessment approach was used for both effect and impact estimations. Caution is therefore recommended when using effect estimates from the literature to assess health impacts of air pollution in actual contexts.

Keywords: $\mathrm{PM}_{10}, \mathrm{PM}_{2.5}$, Health impact assessment, Natural mortality, Short-term effects

\footnotetext{
*Correspondence: simone.giannini.7@gmail.com

'Environmental Health Reference Centre, Regional Agency for Environmental

Protection and Energy of Emilia-Romagna, Via Begarelli 13, 41121 Modena,

Italy

${ }^{2}$ Department of Statistics, University of Bologna, Bologna, Italy

Full list of author information is available at the end of the article
} 


\section{Background}

Scientific evidence that ambient air pollution affects human health has increased since 2000, with several studies performed in the fields of epidemiology, clinical medicine and toxicology [1-4]. Epidemiological research has systematically documented the association of high air pollutant concentrations with the occurrence of a wide spectrum of both acute and chronic adverse effects on the health of population living in urban areas [5-7]. Large meta-analyses conducted in the United States and Europe indicate that exposure to air pollution levels currently observed in urban contexts is associated with short-term increase in mortality and morbidity. Evidence of an effect is substantial for particulate matter, in particular for particles $\leq 10 \mu \mathrm{m}$ and $\leq 2.5 \mu \mathrm{m}$ in diameter $\left(\mathrm{PM}_{10}\right.$ and $\mathrm{PM}_{2.5}$, respectively) $[6,8-17]$.

Different epidemiological studies conducted in various places around the world have led to consistent findings, supporting the causal interpretation of the effect measures and the absence of major bias [18]. This consistency provides the basis for reliable health impact assessments [19-22], which are crucial for addressing public health policies in a context where the magnitude of the effects is small (e.g. mortality from all causes was estimated to increase by $0.2-$ $0.8 \%$ per $10 \mu \mathrm{g} / \mathrm{m}^{3}$ increase in the daily concentration of airborne particles [6, 8-17]) but exposure is widespread.

Several projects have considered short-term impact of air pollution in Italy during the last decades $[8,10,11$, 15, 23, 24]. The MISA study focused on 11 Italian cities for the period 1996-2002, reporting that around 1.5\% of deaths from natural causes were attributable to $\mathrm{PM}_{10}$ levels greater than $11.9 \mu \mathrm{g} / \mathrm{m}^{3}$ [8]. The EpiAir2 project, studying data from 25 major Italian cities, highlighted that $0.9 \%$ and $0.8 \%$ of natural deaths were attributable to levels of $\mathrm{PM}_{10}$ and $\mathrm{PM}_{2.5}$ exceeding respectively the limits of 20 and $10 \mu \mathrm{g} / \mathrm{m}^{3}$ recommended by the World Health Organization (WHO) [24]. Another analysis on the air pollution effects in the Lombardy region for the period 2003-2006 found that 1.4\% of natural deaths were attributable to annual average levels of $\mathrm{PM}_{10}$ higher than $20 \mu \mathrm{g} / \mathrm{m}^{3}$ [23].

This paper aims at contributing to the discussion on the short-term impact of air pollution on human health, providing an evaluation of the number of deaths attributable to high levels of $\mathrm{PM}_{10}$ and $\mathrm{PM}_{2.5}$ in the EmiliaRomagna region, one of the most polluted areas in Europe $[25,26]$. The recent $\mathrm{PM}_{10}$ and $\mathrm{PM}_{2.5}$ concentration excesses observed in December 2015 and January 2016 in this region stressed the need of performing this kind of impact assessment, in order to inform policies of emissions reduction and plans for population's health protection.

The paper also focuses on exposure assessment. Exposure assessment is preliminary to health impact assessment and using different models or approaches to quantify population exposure can produce very different results. In most studies, the impact of air pollution on health is evaluated by considering the air pollution levels

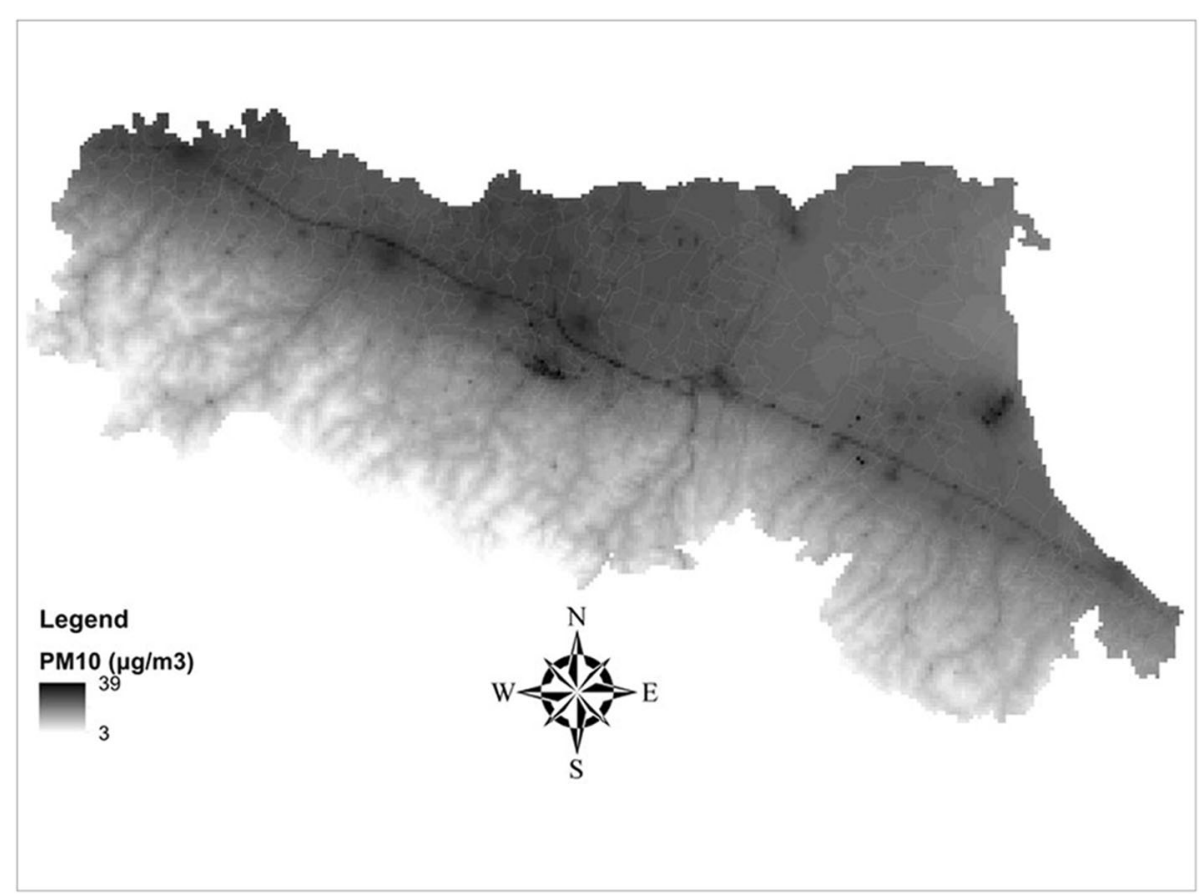

Fig. 1 Annual mean levels of $\mathrm{PM}_{10}\left(\mu \mathrm{g} / \mathrm{m}^{3}\right)$ in the Emilia-Romagna region, 2010 
measured by stations belonging to urban monitoring networks [19-22, 24]. This approach has the advantage of relying on observed concentrations, but it could lead to incorrect impact estimates if the monitor location does not allow detecting the actual population exposure. Moreover, it could be unfeasible if the interest is in extra-urban areas where data from monitors are usually unavailable. In this situation, models are needed to predict air pollutants concentrations [23, 27-29].

In this paper, we adopted and compared alternative exposure assessment approaches, considering air pollution levels measured by background or traffic monitoring stations or a combination of both, and using the air pollutant levels predicted for the entire region at a very fine spatial resolution using a model developed by the Environmental Protection Agency of the Emilia-Romagna region (ARPAE-ER) [30]. Our aim was not to draw conclusions about the best option to quantify population exposure, but to evaluate the sensitivity of the results, intended as the robustness of effect and impact estimates to different exposure assessment approaches.

\section{Methods}

\section{Study population and data collection}

The Emilia-Romagna region is located in the Po Valley, covers an area of $22447 \mathrm{~km}^{2}$ in North-Eastern Italy and includes nine provinces and 348 municipalities, with 4.3 million inhabitants.

Daily counts of deaths from natural causes (ICD-9 001-799 or ICD-10 A00-R99) for the period 2006-2010 were collected for the population aged 35 years or over of the nine provincial capitals (Bologna, Modena, Parma, Reggio Emilia, Ravenna, Rimini, Ferrara, Forlì, and Piacenza), each one having a population of more than 100000 inhabitants. Only deaths of individuals occurring in their town of residence were considered [15].

The total number of deaths in 2010 was also collected for all municipalities across the region. In this case, deaths occurring outside the city of residence were not excluded from the count. All mortality data were extracted from the Regional Health Information System and collected according to a common protocol.

For each municipality in the region, we considered the amount of total population and the percentage of the population of each census block from the available population census.

The daily time series of air pollution measurements, temperature and relative humidity for the period 2006-2010 for the nine provincial capitals were provided by the air quality and meteorological monitoring networks of the ARPAE-ER.

Estimates of the mean annual levels of $\mathrm{PM}_{10}$ and $\mathrm{PM}_{2.5}$ in the Emilia Romagna region for the year 2010 at $1 \times 1$ $\mathrm{km}$ spatial resolution were provided by ARPAE-ER using the NINFA-PESCO modelling suite (Fig. 1): a chemistrytransport model corrected through a Kriging approach, by using the observed data arising from the background monitoring stations located in the region [30].

\section{Exposure assessment}

For each air pollutant, environmental data in the 9 provincial capitals were collected from monitors located in the city area. To satisfy measurement continuity over the study period, all monitors included in the study were required to have at least $75 \%$ complete information for each season (warm season: from April to September; cold season: from October to March). By averaging information from the selected monitors, we obtained a unique daily time series of exposure for each pollutant and city [31].

$\mathrm{PM}_{10}$ data for the period 2006-2010 were available for all cities except Ferrara (for Piacenza, the time series was limited to 2007-2010). For each city, three different definitions of exposure were considered for $\mathrm{PM}_{10}$ : "background" exposure, based only on concentrations measured by background monitoring stations, "traffic" exposure, based only on concentrations measured by traffic monitoring stations, and "average" exposure, based on concentrations measured by both types of monitors used in the two previous calculations.

$\mathrm{PM}_{2.5}$ data for the period 2008-2010 were also collected; for Piacenza, Ferrara and Ravenna they were not available for the entire 3-year period. Only background monitoring stations were available for this pollutant.

To obtain homogeneous values of exposure for all the municipalities of the region, an annual average exposure in 2010 for both pollutants was calculated by integrating the air pollutant levels predicted in the $1 \times 1 \mathrm{~km}$ cells by the NINFA-PESCO modelling suite. This model was calibrated using the air pollutant levels measured by the background monitors. Starting from the cell values, a population-weighted (PW) average was calculated for each municipality, assuming a uniform distribution of the inhabitants within each census block. The PW averages were obtained using ArcMap 10.1 software [32].

\section{Statistical analysis}

The statistical analysis was performed in two steps. First, we estimated the regional short-term effects of the pollutants in the years 2006-2010, using data from the major cities in the region and assuming homogeneity of the effects during the study period; second, health impact assessment was carried out for the period 2006-2010 on the nine provincial capitals and for the year 2010 on all municipalities of the region.

\section{Effect estimates}

In order to estimate the effect of the two air pollutants on mortality, we firstly performed city-specific analyses 
on the nine provincial capitals according to the same protocol; then we combined the first stage city-specific estimates in a Bayesian random effects meta-analysis.

We estimated the short-term effects of $\mathrm{PM}_{10}$ and $\mathrm{PM}_{2.5}$ separately for each city, considering daily deaths of the resident population occurring inside the cities. This way, we avoided the possible bias of considering persons who did not experience the air pollutant exposure in the city.

We adopted the average of the current-day and of the previous-day concentrations (lag $0-1$ ) as indicator of $\mathrm{PM}_{10}$ and $\mathrm{PM}_{2.5}$ exposure $[10,11,23,24]$. We specified over-dispersed Poisson regression models on the daily counts of natural deaths, accounting for seasonality through an interaction term between year, month and day of week (this approach is equivalent to a timestratified case-crossover approach) [33]. Analyses were also adjusted for temperature, population decrease during summer, holidays and influenza epidemic [15]. Regarding temperature adjustment, two different regression splines were fitted: one for temperatures below and one for temperatures above the city-specific median. The first spline was defined on the average temperature calculated over the previous 6 days (lag 1-6), whereas the second spline was defined on the lag 0-1 apparent temperature, which is a linear combination of temperature and relative humidity [15]. A three-level variable was included in the model to account for the population decrease during summer: this variable was equal to 2 in the 2 -weeks centred on 15 August (Italian cities are largely deserted during these weeks), equal to 1 from 16 July to 31 August with the exception of the aforementioned 2-week period, and equal to 0 elsewhere. Dummy variables were introduced to model the effect of holidays and of influenza epidemics, defined according to the Italian national influenza surveillance system.

The effects of $\mathrm{PM}_{10}$ and $\mathrm{PM}_{2.5}$ were separately estimated from one-pollutant models. Analyses were performed using R 3.0.1 software [34].

As a second step, a Bayesian random-effects metaanalysis was specified to combine the city-specific estimates, and a sample from the joint posterior distribution of the model parameters was obtained using WinBugs software $[35,36]$. Bayesian meta-analysis provided an estimate of the posterior overall effect, which is a combination of the first stage city-specific estimates, and an estimate of the shrunken city-specific effects, that borrow strength from all locations, while reflecting heterogeneity among cities [37]. The posterior distribution of the $I^{2}$ index, which represents the percentage of total variability explained by between-city heterogeneity, was also obtained.

The effect estimates were expressed as percentage variation in natural mortality associated with a $10 \mu \mathrm{g} / \mathrm{m}^{3}$ increase of exposure. The posterior distributions of the percentage increases were summarized in terms of posterior mean, 50 and $90 \%$ credibility intervals (the $(1-\alpha) \%$ credibility interval $(\mathrm{CrI})$ is defined as the interval between the $(\alpha / 2)^{\text {th }}$ and the $(1-\alpha / 2)^{\text {th }}$ percentiles of the posterior distribution) [38, 39].

For PM10, separated analyses were performed using the three measures of exposure based on different selections of the available monitoring stations (see Exposure assessment section).

For PM2.5 only the analysis on the "background" exposure (the only available one) was conducted.

\section{Health impact assessment}

Short-term impacts of high levels of $\mathrm{PM}_{10}$ and $\mathrm{PM}_{2.5}$ on mortality were estimated both at city and regional level. The impact was quantified in terms of attributable deaths (AD) and attributable community rate (ACR) (number of $\mathrm{AD}$ over the exposed population) per year $[40,41]$.

In order to estimate $\mathrm{AD}$, the macro and micro approaches, proposed by Baccini et al., were used [23]. The macro approach allowed us to estimate the number of deaths attributable to annual levels of air pollutant $\left(\mathrm{PM}_{10}\right.$ or $\left.\mathrm{PM}_{2.5}\right)$ exceeding a certain value $V$ :

$$
A D_{i}=y_{i}-y_{i 0}=y_{i}-y_{i} / \exp \left(\beta_{i}^{*}\left(x_{i}-V\right)\right),
$$

where $i$ labels the city, $y_{i}$ is the observed annual number of deaths, $y_{i 0}$ is the baseline annual number of deaths at the counterfactual level $V, x_{i}$ is the annual average level of air pollutant and $\beta_{i}^{*}$ is the coefficient expressing the effect of air pollution on a $\log$ scale. If $x_{i}<V, A D_{i}$ was set to $0 . A D_{i}$ can be interpreted as the number of deaths which could have been prevented if the annual average of the air pollutant was equal to $V$.

In the micro approach, $\mathrm{AD}$ calculation was performed day-by-day, using the daily time series of mortality and air pollutant concentration: this analysis allowed us to evaluate the impact of exposure to daily peaks of air pollution. It should be noticed that, if the correlation between daily mortality and daily exposure is small, the macro approach approximates the results that one would obtain by applying a day-by-day micro approach after defining counterfactual daily values consistent with the counterfactual value defined for the annual average [23].

For the nine provincial capitals, we estimated the impact for the period 2006-2010 (2008-2010 for $\mathrm{PM}_{2.5}$ ) using the "background" exposure and the corresponding shrunken estimates of the air pollutant effect, when available. If for a city the shrunken estimate was not available, the overall meta-analytic estimate was employed [23]. For $\mathrm{PM}_{10}$ "average" and "traffic" exposures were also considered. 
The impact at regional level was estimated for the year 2010. In this case, we considered the exposures predicted by the NINFA-PESCO model and AD calculation was carried out adopting the "background" overall metaanalytic estimate as effect estimate for all municipalities, except provincial capitals for which the shrunken estimates were used, if available. To estimate the impact at regional level, we considered all deaths, including those occurring outside the municipality of residence, in order to avoid impact in small municipalities without hospitals being underestimated.

Counterfactuals We assessed the impact under different definitions of the value $\mathrm{V}$, corresponding to different emission reduction scenarios. These scenarios were similar to those reported in a study conducted in the Lombardy region for the 2003-2006 period [23]. For $\mathrm{PM}_{10}$, the following reduction scenarios (RS) were defined:

RS1-PM $\mathrm{P}_{10}$ : the annual average concentration does not exceed the WHO Air Quality Guideline value of 20 $\mu \mathrm{g} / \mathrm{m}^{3}[42]$;

RS2-PM $\mathrm{P}_{10}$ : the annual average concentration is equal to that observed at the "Febbio" monitoring station in the mountain town of Villa Minozzo (province of Reggio Emilia), a non-urban area;

RS3-PM $M_{10}$ : daily concentrations do not exceed the limit of $50 \mu \mathrm{g} / \mathrm{m}^{3}$ for more than 35 days per year, corresponding to the European Union (EU) limit for daily averages [43].

For $\mathrm{PM}_{2.5}$, the following RS was considered:

RS1-PM 2.5 : the annual average concentration does not exceed $10 \mu \mathrm{g} / \mathrm{m}^{3}$ corresponding to the WHO Air Quality Guideline value [42].

While the impacts under the RS1 and RS2 scenarios were evaluated using the macro approach, the number of attributable deaths under the RS3-PM 10 scenario was estimated by averaging 1000 different pseudo-data obtained by constraining to $50 \mu \mathrm{g} / \mathrm{m}^{3}$ different random sets of days exceeding this value, so that the number of days with a concentration above the limit was set at 35 per year in each simulation. This calculation required the micro approach on daily data [23], so it was applied only for the nine provincial capitals, being daily data available only for these cities.

\section{Results}

The total population of the 9 provincial capitals (Bologna, Modena, Parma, Reggio Emilia, Ravenna, Rimini, Ferrara, Forlì, and Piacenza) counted over 1.5 million; Bologna was the biggest city and Piacenza the smallest (Table 1). In these cities the air pollution levels measured by the traffic monitors were higher than those measured by the background monitors, Ravenna being the only exception. For this city, the greater level of air pollutant measured by the background monitor was possibly due to the fact that this monitor is located close to the harbor. Ravenna is a city near the sea, with a relevant industrial area and considerable transportation of inert materials due to the harbor activities. Considering the "background" exposure level during the period 2006-2010, all nine capitals exceeded the WHO annual limits of $20 \mu \mathrm{g} / \mathrm{m}^{3}$ for $\mathrm{PM}_{10}$ and $10 \mu \mathrm{g} / \mathrm{m}^{3}$ for $\mathrm{PM}_{2.5}$. Only Modena exceeded the EU limit of $40 \mu \mathrm{g} / \mathrm{m}^{3}$ for $\mathrm{PM}_{10}$ [43], when considering both the "traffic" and "average" exposure levels. For this reason, scenarios based on the EU limit of $40 \mu \mathrm{g} / \mathrm{m}^{3}$ for $\mathrm{PM}_{10}$ annual average level were not considered. Overall, in the nine capital cities the annual levels of $\mathrm{PM}_{10}$ obtained by averaging the cell values predicted by the NINFA-PESCO model were lower than those measured by the background monitors $\left(29.8 \mu \mathrm{g} / \mathrm{m}^{3}\right.$ vs $\left.32.2 \mu \mathrm{g} / \mathrm{m}^{3}\right)$. Differences were negligible for $\mathrm{PM}_{2.5}$. The $\mathrm{PW}$ average predicted annual concentrations of $\mathrm{PM}_{10}$ and $\mathrm{PM}_{2.5}$ over the region were $27.3 \mu \mathrm{g} / \mathrm{m}^{3}$ and $18.6 \mu \mathrm{g} / \mathrm{m}^{3}$, respectively.

When considering the "background" exposure, the pooled meta-analytic estimate of the percentage variation in natural mortality was 0.58 for each $10 \mu \mathrm{g} / \mathrm{m}^{3}$ increase in $\mathrm{PM}_{10}$ concentration $(90 \% \mathrm{CrI}:-0.09,1.10)$ and 0.31 for each $10 \mu \mathrm{g} / \mathrm{m}^{3}$ increase in $\mathrm{PM}_{2.5}$ concentration (90\% CrI: $-0.96,1.57$ ) (Table 2). The heterogeneity among cities was low, but slightly higher for $\mathrm{PM}_{10}\left(I^{2}=\right.$ 2.77, 90\% CrI: $0.08,53.78)$ than for $\mathrm{PM}_{2.5}\left(I^{2}=1.30,90 \%\right.$ CrI: 0.03, 40.39). The shrunken percentage variations varied from 0.43 (Ravenna) to 0.71 (Piacenza) for $\mathrm{PM}_{10}$, and from 0.20 (Parma and Modena) to 0.47 (Reggio Emilia) for $\mathrm{PM}_{2.5}$.

In order to check the sensitivity of the effect estimates to the specific subset of cities included in the meta-analysis, we applied a leave-one-out approach. When excluding one at time each capital city from the meta-analysis, the overall percentage variation varied from 0.4 to $0.8 \%$ (data not reported) for $\mathrm{PM}_{10}$, that was in any case within the credibility interval of the overall meta-analytic effect.

The last three lines of Table 2 show the sensitivity analysis on different specifications of the exposure levels. The estimate of the overall meta-analytic effect based on "background" exposure was higher compared to the other two modalities. When $\mathrm{PM}_{10}$ exposure was defined using only traffic monitoring stations, the overall meta-analytic effect estimate was substantially unchanged compared to that obtained with the "average" exposure (Table 2).

Table 3 shows the short term impact of $\mathrm{PM}_{10}$ and $\mathrm{PM}_{2.5}$ on mortality in the provincial capitals during the period 2006-2010, evaluated under different emission 
Table 1 Population characteristics and air pollutant levels, Emilia Romagna region (2006-2010)

\begin{tabular}{|c|c|c|c|c|c|c|c|c|c|}
\hline \multirow[t]{3}{*}{ City } & \multirow[t]{3}{*}{$\begin{array}{l}\text { Population } \\
\text { in } 2011\end{array}$} & \multirow{3}{*}{$\begin{array}{l}\text { Annual average } \\
\text { of deaths } \\
\text { (occurred in the } \\
\text { municipality of } \\
\text { residence) }\end{array}$} & \multirow{3}{*}{$\begin{array}{l}\text { Percentage } \\
\text { of deaths } \\
\text { occurred } \\
\text { outside } \\
\text { municipality } \\
\text { of residence }\end{array}$} & \multicolumn{4}{|c|}{$\begin{array}{l}\mathrm{PM}_{10} \text { concentration } \\
\mu \mathrm{g} / \mathrm{m}^{3}\end{array}$} & \multicolumn{2}{|l|}{$\begin{array}{l}\mathrm{PM}_{2.5} \text { concentration } \\
\mu \mathrm{g} / \mathrm{m}^{3}\end{array}$} \\
\hline & & & & \multicolumn{3}{|c|}{$\begin{array}{l}\text { Monitoring station } \\
2006-2010 \\
\text { (mean } \pm \text { sd) }\end{array}$} & \multirow{2}{*}{$\begin{array}{l}\text { PW-average } \\
\text { level } \\
2010 \\
\text { (mean) }\end{array}$} & \multirow{2}{*}{$\begin{array}{l}\text { Monitoring station } \\
2006-2010 \\
\text { mean } \pm \text { sd } \\
\text { "background" } \\
\text { exposure }\end{array}$} & \multirow{2}{*}{$\begin{array}{l}\text { PW-average } \\
\text { level } \\
2010 \\
\text { (mean) }\end{array}$} \\
\hline & & & & $\begin{array}{l}\text { "background" } \\
\text { exposure }\end{array}$ & $\begin{array}{l}\text { "average" } \\
\text { exposure }\end{array}$ & $\begin{array}{l}\text { "traffic" } \\
\text { exposure }\end{array}$ & & & \\
\hline Piacenza & 100,331 & 1,004 & 12.8 & $37.0 \pm 21.8$ & $38.5 \pm 22.6$ & $40.8 \pm 24.4$ & 33.1 & $24.9 \pm 14.9^{a}$ & 22.5 \\
\hline Parma & 175,895 & 1,709 & 8.6 & $34.8 \pm 20.6$ & $35.4 \pm 20.2$ & $36.4 \pm 21.1$ & 31.4 & $21.0 \pm 15.8$ & 20.6 \\
\hline Reggio Emilia & 162,082 & 1,304 & 12.0 & $33.2 \pm 19.6$ & $37.1 \pm 21.1$ & $38.9 \pm 22.2$ & 31.0 & $22.6 \pm 15.1$ & 20.8 \\
\hline Modena & 179,149 & 1,720 & 5.6 & $36.5 \pm 23.1$ & $41.0 \pm 24.1$ & $42.8 \pm 24.7$ & 32.7 & $21.7 \pm 15.2$ & 20.6 \\
\hline Bologna & 371,337 & 3,845 & 15.0 & $25.8 \pm 17.2$ & $38.5 \pm 21.6$ & $38.5 \pm 21.5$ & 28.9 & $16.8 \pm 12.3$ & 15.3 \\
\hline Ferrara & 132,545 & 1,577 & 6.0 & $27.2 \pm 15.9^{b}$ & $37.6 \pm 22.7$ & $37.5 \pm 22.7$ & 27.9 & $20.8 \pm 15.1^{b}$ & 20.5 \\
\hline Ravenna & 153,740 & 1,328 & 10.5 & $30.8 \pm 14.8$ & $29.8 \pm 15.5$ & $28.9 \pm 16.9$ & 30.0 & $16.8 \pm 11.5^{c}$ & 19.6 \\
\hline Forlì & 116,434 & 940 & 20.2 & $29.4 \pm 17.8$ & $32.1 \pm 18.3$ & $35.0 \pm 19.5$ & 26.6 & $17.7 \pm 13.2$ & 19.5 \\
\hline Rimini & 139,601 & 1,145 & 11.3 & $34.7 \pm 19.8$ & $34.9 \pm 18.5$ & $35.4 \pm 18.3$ & 27.4 & $21.9 \pm 17.5$ & 19.5 \\
\hline 9 cities & $1,531,094$ & 14,572 & 11.6 & $32.2 \pm 19.0$ & $36.1 \pm 20.5$ & $37.1 \pm 21.3$ & 29.8 & $20.5 \pm 14.5$ & 19.2 \\
\hline $\begin{array}{l}\text { Emilia } \\
\text { Romagna region }\end{array}$ & $4,342,135$ & $44,844^{*}$ & & - & & & 27.3 & - & 18.6 \\
\hline
\end{tabular}

Monitoring period from: a) $14 / 09 / 2009$; b) $20 / 11 / 2008$; c) $03 / 04 / 2009$

Abbreviations: $P W$ population-weighted

*: this value includes deaths occurred outside the municipality of residence

reduction scenarios. The results refer to exposures assessed using background monitoring stations. Exceeding the WHO limit for the annual average concentration of $\mathrm{PM}_{10}$ had a short term impact of 91 deaths per year in these cities (AD ranged from 5 per year in Ravenna to 14 per year in Piacenza), corresponding to 5.9 deaths per 100000 inhabitants per year. Exceeding the WHO limit of $10 \mu \mathrm{g} / \mathrm{m}^{3}$ for the annual average of $\mathrm{PM}_{2.5}$, caused 46 deaths per year in the provincial capitals, corresponding to 3.0 deaths per 100000 inhabitants per year. A negligible short term impact was estimated considering the scenario of EU limit exceedances for daily concentrations of $\mathrm{PM}_{10}$. On the contrary, the estimated short term impact when fixing the counterfactual value to the annual average concentration observed in non-urban areas $\left(9.1 \mu \mathrm{g} / \mathrm{m}^{3}\right)$ was very high: $179 \mathrm{AD}$, corresponding to 11.7 deaths per 100000 inhabitants per year.

The results of the sensitivity analysis which compared short term impacts estimated under different exposure specifications are reported in the last three rows of Table 3. We found that $\mathrm{AD}$ were largely similar when considering the three different definitions of exposure and the counterfactual value of $20 \mu \mathrm{g} / \mathrm{m}^{3}$ : we estimated $86 \mathrm{AD}$ per year (50\% CrI: 19, 150) for the "average" exposure, 91 (50\% CrI: 41, 140) for the "background" exposure and 89 (50\% CrI: 21, 155) for the "traffic" exposure. This was partly expected, because the lowest "traffic" effect estimates were combined with higher air pollution concentrations, whereas the highest "background" effect estimates were combined with lower air pollution concentrations. A certain discrepancy between "background" and "traffic" impacts arose under the counterfactual value of $9.1 \mu \mathrm{g} / \mathrm{m}^{3}$, but the credibility intervals largely overlapped.

The impact estimates at regional level for the year 2010 (using the NINFA-PESCO exposure) are shown in Table 4. The impact estimates in the provincial capitals using the NINFA-PESCO exposure appeared to be similar to those obtained for the period 2006-2010 using data from the monitoring stations. Exceeding the WHO limit of $20 \mu \mathrm{g} / \mathrm{m}^{3}$ for the annual average level of $\mathrm{PM}_{10}$ was responsible for 190 deaths per year in the region (AD ranged from 7 per year in cities with less than 5 000 inhabitants to 104 per year in cities with more than 50000 inhabitants) and exceeding the WHO limit of 10 $\mu \mathrm{g} / \mathrm{m}^{3}$ for the annual average level of $\mathrm{PM}_{2.5}$ was responsible for 123 deaths per year (AD ranged from 7 per year in cities with less than 5000 inhabitants to 56 per year in cities with more than 50000 inhabitants).

\section{Discussion}

The present work assessed the short-term impact of high concentrations of $\mathrm{PM}_{10}$ and $\mathrm{PM}_{2.5}$ on mortality in the Emilia-Romagna region. We found that in the cities with more than 100000 inhabitants, during the period 2006-2010, exceeding the WHO limit for the annual average level of $\mathrm{PM}_{10}$ produced 5.9 deaths per 100000 inhabitants per year. When considering $\mathrm{PM}_{2.5}$, exceeding the WHO limit of $10 \mu \mathrm{g} / \mathrm{m}^{3}$ was annually responsible for 3.0 deaths per 100000 inhabitants. 
Table 2 Shrunken city-specific effects ${ }^{\mathrm{a}}$ and overall meta-analytic effect of $\mathrm{PM}_{10}$ and $\mathrm{PM}_{2.5}$ on natural mortality and corresponding 50 and 90\% credibility intervals, Emilia-Romagna region (2006-2010)

\begin{tabular}{|c|c|c|c|c|c|c|}
\hline \multirow[t]{2}{*}{ City $^{b}$} & \multicolumn{3}{|l|}{$\mathrm{PM}_{10}$} & \multicolumn{3}{|l|}{$\mathrm{PM}_{2.5}{ }^{\mathrm{d}}$} \\
\hline & $\begin{array}{l}\% \text { variation } \\
\text { (Posterior mean) }\end{array}$ & $\begin{array}{l}50 \% \text { Credibility } \\
\text { Interval }\end{array}$ & $\begin{array}{l}90 \% \text { Credibility } \\
\text { Interval }\end{array}$ & $\begin{array}{l}\text { \% variation } \\
\text { (Posterior mean) }\end{array}$ & $\begin{array}{l}50 \% \text { Credibility } \\
\text { Interval }\end{array}$ & $\begin{array}{l}90 \% \text { Credibility } \\
\text { Interval }\end{array}$ \\
\hline Piacenza $^{c}$ & 0.71 & $0.39,1.08$ & $-0.03,2.23$ & - & - & - \\
\hline Parma & 0.53 & $0.23,0.84$ & $-0.32,1.28$ & 0.20 & $-0.32,0.75$ & $-1.23,1.54$ \\
\hline Reggio Emilia & 0.64 & $0.32,0.95$ & $-0.15,1.54$ & 0.47 & $-0.09,0.99$ & $-0.92,1.98$ \\
\hline Modena & 0.47 & $0.14,0.77$ & $-0.47,1.15$ & 0.20 & $-0.33,0.76$ & $-1.21,1.56$ \\
\hline Bologna & 0.56 & $0.27,0.85$ & $-0.21,1.25$ & 0.35 & $-0.16,0.86$ & $-0.96,1.66$ \\
\hline Ravenna & 0.43 & $0.05,0.76$ & $-0.22,1.70$ & - & - & - \\
\hline Forlì & 0.62 & $0.31,0.94$ & $-0.22,1.70$ & 0.24 & $-0.33,0.81$ & $-1.26,1.65$ \\
\hline Rimini & 0.64 & $0.34,0.84$ & $-0.12,1.70$ & 0.41 & $-0.17,0.93$ & $-0.99,1.87$ \\
\hline Overall - "Background" exposure & 0.58 & $0.31,0.84$ & $-0.09,1.10$ & 0.31 & $-0.18,0.79$ & $-0.96,1.57$ \\
\hline $1^{2}(\%)$ & 2.77 & $0.48,14.61$ & $0.08,53.78$ & 1.30 & $0.20,7.57$ & $0.03,40.39$ \\
\hline Overall - "Average" exposure & 0.36 & $0.12,0.60$ & $-0.10,0.82$ & - & - & - \\
\hline$I^{2}(\%)$ & 2.40 & $0.48,11.96$ & $0.09,49.07$ & & & \\
\hline Overall - "Traffic" exposure & 0.36 & $0.12,0.60$ & $-0.23,0.95$ & - & - & - \\
\hline $1^{2}(\%)$ & 2.24 & $0.46,10.79$ & $0.09,46.60$ & - & - & - \\
\hline
\end{tabular}

${ }^{a}$ : Effects are expressed as percentage variations in natural mortality associated with an increase of $10 \mu \mathrm{g} / \mathrm{m}^{3}$ in $\mathrm{PM}_{10}$ or $\mathrm{PM} \mathrm{M}_{2.5} \mathrm{concentration}$ at lag $0-1$

b: Ferrara is not reported due to for this city the background levels of exposure were not available for the entire study period

c: Study period for $\mathrm{PM}_{10}$ : 2007-2010

d: Study period: $2008-2010$

While the impact results for $\mathrm{PM}_{10}$ in the provincial capitals were in line with those in the 25 Italian cities participating in the EpiAir2 project (8.4 deaths per 100 000 inhabitants per year) [24], we found that the ACR due to high $\mathrm{PM}_{10}$ levels in the Emilia-Romagna region was lower than that reported in Baccini et al. for the adjoining Lombardy region during the study period 20032006 (12.6 deaths per 100 000) [23]. Similarly, the effects and the impacts estimated for $\mathrm{PM}_{2.5}$, during the same study period, were lower than the national ones (7.4 deaths per 100 000) [24]. These discrepancies are likely due to the fact that our meta-analysis and the cited ones refer to cities that are heterogeneous both in terms of socio-demographic characteristics and exposure levels, use different statistical approaches and focus on different calendar time periods [11].

Our analyses highlighted also an important impact in medium and small-sized municipalities in the region. However, in interpreting this result, it has to pointed out that we extended the overall effect estimate of the metaanalysis on the capital cities to the whole region, including smaller and less polluted areas, so that the presence of a certain degree of bias cannot be ruled out. For $\mathrm{PM}_{10}, 48 \%$ of $\mathrm{AD}$ were estimated among people residing in the nine capital cities, where more than $35 \%$ of the regional total population lives. For $\mathrm{PM}_{2.5}$, this percentage decreased at $38 \%$, because of the lower heterogeneity of the $\mathrm{PM}_{2.5}$ concentrations among large and small municipalities. ACRs for small and medium-sized municipalities (between 5000 and 50000 inhabitants) were lower than ACRs for cities with more than 50000 inhabitants, but not negligible, indicating that the impact was also relevant in the smaller municipalities.

Selecting the "appropriate" monitors is part of the more general issue concerning the use of fixed-site stations to measure population exposure. This issue is related to the problem of exposure misclassification and its effects on the estimated associations [44], but discussing these aspects was beyond the aim of this paper. Objective of the present study was to evaluate the consequence of selecting monitors according to their classification (as background or traffic stations) on effect and impact estimates.

It should be noticed that in general the usual classification of monitors in traffic and background stations could be not informative regarding their ability to measure the actual exposure of the resident population. Usually the air pollutants levels measured by background monitoring stations are considered more appropriate to represent population exposure, but this could not be the case if these monitors are located in urban parks, far from residence areas. On the other hand, traffic monitoring stations could be accounted for if located close to residential areas, even if they generally reflect hot spots of urban pollution.

We found that the $\mathrm{PM}_{10}$ effect estimates were not robust to different exposure assessment approaches. The estimated percentage variation on the capital cities was 
Table 3 Estimated number of deaths attributable (AD) to $\mathrm{PM}_{10}$ and $\mathrm{PM}_{2.5}$ and corresponding attributable community rate (ACR) per 100000 inhabitants under different counterfactual scenarios by capital city (using the "background" exposure) and total (using different exposure assessment approaches), Emilia-Romagna region (2006-2010)

\begin{tabular}{|c|c|c|c|c|c|c|c|c|c|c|c|c|}
\hline \multirow[t]{2}{*}{ City $^{a}$} & \multicolumn{3}{|c|}{$\begin{array}{l}\text { RS1-PM } 10 \\
V=20 \mu \mathrm{g} / \mathrm{m}^{3}\end{array}$} & \multicolumn{3}{|c|}{$\begin{array}{l}\text { RS2-PM } 10 \\
V=9.1 \mu \mathrm{g} / \mathrm{m}^{3}\end{array}$} & \multicolumn{3}{|c|}{$\begin{array}{l}\mathrm{RS} 3-\mathrm{PM}_{10} \\
\mathrm{~V}=\text { annual average obtained if the EU limit } \\
\text { for daily averages is respected }\end{array}$} & \multicolumn{3}{|c|}{$\begin{array}{l}\mathrm{RS} 1-\mathrm{PM}_{2.5} \\
\mathrm{~V}=10 \mu \mathrm{g} / \mathrm{m}^{3}\end{array}$} \\
\hline & $A D$ & $50 \% \mathrm{Crl}$ & ACR & $A D$ & $50 \% \mathrm{Crl}$ & ACR & $A D$ & $50 \% \mathrm{Crl}$ & ACR & $A D$ & $50 \% \mathrm{Crl}$ & ACR \\
\hline Piacenza & 14 & 7,18 & 14.0 & 23 & 11,29 & 22.8 & 2 & 1,2 & 1.7 & 5 & 0,12 & 4.9 \\
\hline Parma & 13 & 6,21 & 7.5 & 23 & 10,36 & 12.9 & 1 & 0,2 & 0.6 & 4 & 0,14 & 2.5 \\
\hline Reggio Emilia & 11 & 6,16 & 7.0 & 21 & 10,29 & 12.6 & 1 & 0,1 & 0.4 & 7 & 0,16 & 4.1 \\
\hline Modena & 12 & 4,22 & 6.7 & 20 & 7,36 & 11.1 & 1 & 0,3 & 0.8 & 5 & 0,15 & 2.6 \\
\hline Bologna & 12 & 6,19 & 3.3 & 35 & 17,54 & 9.5 & 0 & 0,1 & 0.1 & 9 & 0,22 & 2.5 \\
\hline Ferrara & 7 & 4,9 & 4.9 & 16 & 9,24 & 12.3 & 0 & 0,0 & 0.0 & 6 & 0,13 & 4.2 \\
\hline Ravenna & 5 & 1,11 & 3.0 & 9 & 1,22 & 5.9 & 0 & 0,0 & 0.0 & 3 & 0,7 & 1.9 \\
\hline Forlì & 6 & 3,8 & 4.9 & 12 & 6,18 & 10.6 & 0 & 0,0 & 0.2 & 2 & 0,6 & 1.8 \\
\hline Rimini & 11 & 6,16 & 8.2 & 20 & 10,28 & 14.1 & 1 & 0,1 & 0.7 & 5 & 0,13 & 3.7 \\
\hline $\begin{array}{l}9 \text { cities - "Background" } \\
\text { exposure }\end{array}$ & 91 & 41,140 & 5.9 & 179 & 81,275 & 11.7 & 7 & 3,10 & 0.4 & 46 & 0,119 & 3.0 \\
\hline $\begin{array}{l}9 \text { cities - "Average" } \\
\text { exposure }^{\text {b }}\end{array}$ & 86 & 19,150 & 5.6 & 141 & 31,247 & 9.2 & 10 & 2,18 & 0.7 & - & - & - \\
\hline $\begin{array}{l}9 \text { cities - "Traffic" } \\
\text { exposure }\end{array}$ & 89 & 21,155 & 5.8 & 143 & 33,251 & 9.4 & 12 & 3,21 & 0.8 & - & - & - \\
\hline
\end{tabular}

Abbreviations: $V$ counterfactual value, $A D$ attributable deaths, $C r l$ credibility interval, $A C R$ attributable community rate;

$\mathrm{RS} 1-\mathrm{PM}_{10}=$ reduction scenario where $\mathrm{V}$ is equal to $20 \mu \mathrm{g} / \mathrm{m}^{3}$ annual average (WHO Air Quality Guideline threshold);

$\mathrm{RS} 2-\mathrm{PM}_{10}=$ reduction scenario where $\mathrm{V}$ is equal to annual average concentrations observed in non-urban areas;

RS3-PM $M_{10}=$ reduction scenario where $V$ is equal to annual average obtained if only 35 days, per year, concentrations exceeding $50 \mu \mathrm{g} / \mathrm{m}^{3}$;

$\mathrm{RS} 1-\mathrm{PM}_{2.5}=$ reduction scenario where $\mathrm{V}$ is equal to $10 \mu \mathrm{g} / \mathrm{m}^{3}$ annual average (WHO Air Quality Guideline threshold)

a: For each city, "background" exposure and "background "effect estimate were used, with the exception of Ferrara for which the "background" overall metaanalytic estimate was used

${ }^{b}$ : The low/upper limit of the credibility interval was calculated as the sum of the low/upper limits of the city-specific credibility intervals

Table 4 Population weighted (PW)-average concentration of $\mathrm{PM}_{10}$ and $\mathrm{PM}_{2.5}$ from the NINFA-PESCO model, estimated number of attributable deaths (AD) with 50\% credibility interval (Crl), and attributable community rate (ACR) per 100000 inhabitants under different counterfactual scenarios, Emilia-Romagna region (2010)

\begin{tabular}{|c|c|c|c|c|c|c|c|c|c|c|c|}
\hline & \multirow[t]{2}{*}{$\begin{array}{l}\mathrm{PM}_{10} \\
\left(\mu \mathrm{g} / \mathrm{m}^{3}\right)\end{array}$} & \multicolumn{3}{|c|}{$\begin{array}{l}\text { RS1-PM } 10 \\
V=20 \mu \mathrm{g} / \mathrm{m}^{3}\end{array}$} & \multicolumn{3}{|c|}{$\begin{array}{l}\text { RS2-PM } 10 \\
V=9.1 \mu \mathrm{g} / \mathrm{m}^{3}\end{array}$} & \multirow[t]{2}{*}{$\begin{array}{l}\mathrm{PM}_{2.5} \\
\left(\mu \mathrm{g} / \mathrm{m}^{3}\right)\end{array}$} & \multicolumn{3}{|c|}{$\begin{array}{l}\text { RS1-PM } 2.5 \\
V=10 \mu \mathrm{g} / \mathrm{m}^{3}\end{array}$} \\
\hline & & $\overline{A D}$ & $50 \% \mathrm{Crl}^{\mathrm{a}}$ & ACR & $\overline{A D}$ & $50 \% \mathrm{Crl}^{\mathrm{a}}$ & $A C R$ & & $\overline{A D}$ & $50 \% \mathrm{Crl}^{\mathrm{a}}$ & ACR \\
\hline Emilia-Romagna region & 27.3 & 190 & 94,283 & 4.4 & 456 & 229,675 & 10.5 & 18.6 & 123 & 0,304 & 2.8 \\
\hline nine capital cities & 29.8 & 91 & 41,139 & 5.9 & 191 & 86,292 & 12.5 & 19.2 & 47 & 0,123 & 3.1 \\
\hline Other cities & 25.9 & 99 & 53,144 & 3.5 & 265 & 143,383 & 9.4 & 18.3 & 75 & 0,182 & 2.7 \\
\hline \multicolumn{12}{|l|}{$\begin{array}{l}\text { By municipality } \\
\text { dimension }\end{array}$} \\
\hline$>50000$ & 29.5 & 104 & 48,158 & 5.7 & 222 & 103,338 & 12.2 & 19.2 & 56 & 0,144 & 3.1 \\
\hline $20000-50000$ & 27.5 & 23 & 12,33 & 4.1 & 57 & 31,82 & 10.1 & 19.2 & 16 & 0,39 & 2.9 \\
\hline $10000-20000$ & 26.8 & 31 & 17,45 & 3.7 & 79 & 43,115 & 9.4 & 18.9 & 23 & 0,56 & 2.8 \\
\hline $5000-10000$ & 26.2 & 25 & 13,36 & 3.6 & 66 & 45,87 & 9.4 & 19.0 & 20 & 0,48 & 2.8 \\
\hline$<5000$ & 20.2 & 7 & 4,10 & 1.7 & 32 & 16,51 & 7.5 & 13.7 & 7 & 0,17 & 1.7 \\
\hline
\end{tabular}

Abbreviations: $V$ counterfactual value, $A D$ attributable deaths, $C r l$ credibility interval, $A C R$ attributable community rate;

$\mathrm{RS} 1-\mathrm{PM}_{10}=$ reduction scenario where $\mathrm{V}$ is equal to $20 \mu \mathrm{g} / \mathrm{m}^{3}$ annual average (WHO Air Quality Guideline threshold);

$\mathrm{RS} 2-\mathrm{PM}_{10}=$ reduction scenario where $\mathrm{V}$ is equal to annual average concentrations observed in non-urban areas;

$\mathrm{RS} 1-\mathrm{PM}_{2.5}=$ reduction scenario where $\mathrm{V}$ is equal to $10 \mu \mathrm{g} / \mathrm{m}^{3}$ annual average (WHO Air Quality Guideline threshold)

${ }^{a}$ : The low/upper limit of the credibility interval was calculated as the sum of the low/upper limits of the city-specific credibility intervals 
higher when considering the exposure from background monitors than when considering the exposure from traffic monitors. This result was partly expected due to the nature of the regression model and the data pattern. In fact, the correlations between traffic and background daily concentrations were very high (0.92 on average), indicating that both time series were capturing the same underlying phenomenon. This high correlation, coupled with the fact that the ratio between background values and traffic values was always lower than 1 (with the exception of Ravenna), was consistent with the observed ratio between the percentage variations estimated by the Poisson regression models when the two different exposures were used.

A second possible explanation of the observed discrepancy between effect estimates is that higher daily pollutant levels (such as those usually measured by traffic sites) could be actually associated with lower effects, indicating non-linearity of the exposure-response curve on a $\log$ scale. However, it seems difficult to conclude for non-linearity from analyses conducted on general population without focusing on subgroups of people actually exposed to the air pollutant levels measured by the different monitoring stations.

Finally, we cannot exclude that the observed discrepancy between traffic and background percentage variations was partly due to a larger degree of exposure misclassification when using traffic monitors than when using background monitors to assess the exposure level of the resident population. This larger misclassification could have brought to a certain degree of underestimation of the estimated associations.

Roemer and van Wijnen found results in line with ours, reporting larger effects using background stations rather than the traffic ones, when considering black smoke, $\mathrm{CO}, \mathrm{NO}, \mathrm{NO}_{2}$ and $\mathrm{SO}_{2}$ [45]. Also these authors conclude that the lower relative risks associated to traffic concentrations is likely due to the larger range of variation of these measures in respect to the background ones and to exposure misclassification.

In our study we focused also on the sensitivity of the impact estimates to different exposure assessment. Despite the discrepancy in terms of percentage variations, when exposure levels and effect estimates were combined to calculate $\mathrm{AD}$, in particular when the counterfactual value of $20 \mu \mathrm{g} / \mathrm{m}^{3}$ for $\mathrm{PM}_{10}$ was considered, we found that the impact estimates essentially overlapped. In fact, the lower percentage variations estimated for the traffic monitors were coupled with the higher levels of exposure measured by these monitors, and the opposite happened for the background monitors. This indicates a substantial robustness of our impact estimates to different exposure definitions. This robustness also strengthens our results at regional level, when we used the "background" exposure, the only one assuring a homogeneous definition of the air pollutant levels over the region.

It should be stressed that the substantial robustness of the impact estimates relied on the fact that we used the same exposure measures both in effect estimation and impact calculation. This consistency could decay in those studies where impact is assessed by combining effect estimates from the literature with actual air pollutant levels. In our study, combining effect estimates with incongruous exposures would have brought to substantial differences in terms of ACR. For example, when considering the WHO reduction scenario for $\mathrm{PM}_{10}\left(\mathrm{RS} 1-\mathrm{PM}_{10}\right)$, the overall ACR in the nine capital cities would have been equal to 9.4 if "background" effect estimates and "traffic" exposures had been used, and equal to 3.7 if "traffic" effect estimates had been combined with "background" exposures. On the contrary, using the same exposures measure both in effect and impact estimates provided very similar impacts: ACRs were equal to 5.9 and 5.8 under the "background" approach and the "traffic" approach, respectively (Table 3).

\section{Conclusion}

In conclusion, our study confirmed that a reduction in particle concentrations during the study period would have produced significant health benefits in all municipalities of the Emilia Romagna region, from the largest cities to the smallest towns. While the effect estimates were sensitive to the use of different exposure assessment approaches, the impact estimates were more robust, provided that the same exposure definition was used both for effect estimation and attributable deaths calculation. This highlights that caution is required in using effect estimates obtained from the literature to estimate actual impacts, without considering how exposures were calculated.

\section{Abbreviations}

ACR: Attributable community rate; AD: Attributable deaths; ARPAEER: Environmental Protection Agency of Emilia-Romagna region;

Crl: Credibility interval; EU: European Union; ICD: International classification of disease; $\mathrm{PM}_{10}$ : Particulate matter $\leq 10 \mu \mathrm{m}$ in diameter; $\mathrm{PM}_{2.5}$ : Particulate matter $\leq 2.5 \mu \mathrm{m}$ in diameter; PW: Population-weighted; RS: Reduction scenario; WHO: World Health Organization

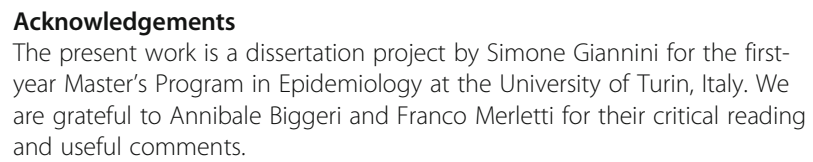
year Master's Program in Epidemiology at the University of Turin, Italy. We are grateful to Annibale Biggeri and Franco Merletti for their critical reading and useful comments.

Funding

No external funding sources have been provided for this study.

\section{Availability of data and materials}

Health data are available at http://www.regione.emilia-romagna.it/sas/rem/ reportistica.htm. Environmental data are available at http://www.arpae.it/ dettaglio_generale.asp?id=2921\&idlivello=1637 for monitoring stations data and http://www.arpae.it/dettaglio documento.asp?id=2988\&idlivello=1692 for maps data. Census data are available on http://www.istat.it/it/archivio/ 
104317. The authors do not wish to share the final datasets because further analysis are ongoing.

\section{Authors' contribution}

SG participated in the study conceiving and design, prepare datasets, performed the statistical analysis and drafted the manuscript. MB participated in the study conceiving and design, coordinated the statistical analysis and drafted the manuscript. AR coordinated the study conceiving and design, helped in statistical analyses and drafted the manuscript. GB prepared datasets and revised the manuscript. GR participated in the design of the study, supported statistical analyses and revised the manuscript. PL participated in study conceiving and design, and revised the manuscript. All authors read and approved the final manuscript.

\section{Competing interests}

The authors declare that they have no competing interests.

\section{Consent for publication}

Not applicable.

\section{Ethics approval and consent to participate}

Not applicable.

\section{Author details}

${ }^{1}$ Environmental Health Reference Centre, Regional Agency for Environmental Protection and Energy of Emilia-Romagna, Via Begarelli 13, 41121 Modena, Italy. ${ }^{2}$ Department of Statistics, University of Bologna, Bologna, Italy. ${ }^{3}$ Department of Statistics, Computer Science, Applications, University of Florence, Florence, Italy. ${ }^{4}$ Department of Clinical Science and Community Health, University of Milan, Milan, Italy. ${ }^{5}$ Institute for Health and Consumer Protection, Joint Research Centre of European Commission, Ispra, VA, Italy. ${ }^{6}$ Hydro Meteorological Service, Regional Agency for Environmental Protection and Energy of Emilia-Romagna, Bologna, Italy. ${ }^{7}$ Regional Center for Environmental Modelling, Regional Agency for Environmental Protection of Friuli Venezia Giuli, Palmanova, Italy.

Received: 13 May 2016 Accepted: 17 January 2017

\section{Published online: 22 February 2017}

\section{References}

1. Brunekreef B, Holgate ST. Air pollution and health. Lancet. 2002;360(9341): 1233-42.

2. Bell ML, Dominici F, Ebisu K, Zeger SL, Samet JL. Spatial and temporal variation in $\mathrm{PM}_{2.5}$ chemical composition in the United States for health effect studies. Environ Health Perspect. 2007;115(7):989-95. doi:10.1289/ehp.9621.

3. Ankley GT, Bennett RS, Erickson RJ, Hoff DJ, Hornung RD, Johnson DR, et al. Adverse outcome pathways: a conceptual framework to support ecotoxicology research and risk assessment. Environ Toxicol Chem. 2010; 29(3):730-41. http://dx.doi.org/10.1002/etc.34.

4. Lee BJ, Kim B, Lee K. Air pollution exposure and cardiovascular disease. Toxicol Res. 2014;30(2):71-5. doi:10.5487/TR.2014.30.2.071.

5. Katsouyanni K, Touloumi G, Samoli E, Gryparis A, Le Tertre A, Monopolis Y, et al. Counfonding and effect modification in the short-term effects of ambient particles on total mortality: results from 29 European cities within the APHEA2 project. Epidemiology. 2001;12(5):521-31.

6. Samoli E, Stafoggia M, Rodopoulou S, Ostro B, Declercq C, Alessandrini E, et al. Association between fine and coarse particles and mortality in mediterranean cities: results from the MED-PARTICLES project. Environ Health Perspect. 2013;121(8):932-8. doi:10.1289/ehp.1206124.

7. Beelen R, Stafoggia M, Raaschou-Nielsen O, Andersen ZJ, Xun WW, Katsouyanni K, et al. Long-term exposure to air pollution and cardiovascular mortality: an analysis of 22 European cohorts. Epidemiology. 2014;25(3):36878. doi:10.1097/EDE.0000000000000076.

8. Biggeri A, Bellini P, Terracini B. Meta-analysis of the Italian studies on shortterm effects of air pollution - MISA 1996-2002 [Article in Italian]. Epidemiol Prev. 2004;28(4-5 Suppl):4-100.

9. Zanobetti A, Schwartz J. The effects of fine and coarse particulate air pollution on mortality: a national analysis. Environ Health Perspect. 2009; 117(6):898-903. doi:10.1289/ehp.0800108.
10. Stafoggia M, Faustini A, Rognoni M, Tessari R, Cadum E, Pacelli B, et al. Air pollution and mortality in ten Italian cities. Results of EpiAir Project [Article in Italian]. Epidemiol Prev. 2009;33(6 Suppl 1):65-76.

11. Biggeri $A$, Baccini M. Short-term effects of air pollution in Italy: risk heterogeneity from 1996-2005 [Article in Italian]. Epidemiol Prev. 2009;33(6 Suppl 1):95-102.

12. Ostro B, Tobias A, Querol X, Alastuey A, Amato F, Pey J, et al. The effects of particulate matter sources on daily mortality: a case-crossover study of Barcelona, Spain. Environ Health Perspect. 2011;119(12):1781-7. doi:10.1289/ehp.1103618.

13. Mallone S, Stafoggia M, Faustini A, Gobi GP, Marconi A, Forastiere F. Saharan dust and association between particulate matter and daily mortality in Rome, Italy. Environ Health Perspect. 2011;119(10):1409-14. doi:10.12989/ehp.1003026.

14. Meister K, Johansson C, Forsberg B. Estimated short-term effects of coarse particles on daily mortality in Stockholm, Sweden. Environ Health Perspect. 2012;120(3):431-6. doi:10.1289/ehp.1103995.

15. Alessandrini ER, Faustini A, Chiusolo M, Stafoggia M, Gandini M, Demaria M, et al. Air pollution and mortality in twenty-five Italian cities: results of the EpiAir2 Project [Article in Italian]. Epidemiol Prev. 2013:37(4-5):220-9.

16. Janssen NAH, Fischer P, Marra M, Ameling C, Casse FR. Short-term effects of PM2.5 and PM2.5-10 on daily mortality in Netherlands. Sci Total Environ. 2013;463-464:20-6. doi:10.1016/j.scitotenv.2013.05.062.

17. Atkinson RW, Kang S, Anderson HR, Mills IC, Walton HA. Epidemiological time series studies of PM2.5 and daily mortality and hospital admissions: a systematic review and meta-analysis. Thorax. 2014;69(7):660-5. doi:10.1136/ thoraxjnl-2013-204492

18. Schwartz J, Austin E, Bind MA, Zanobetti A, Koutrakis P. Estimating causal associations of fine particles with daily deaths in Boston. Am J Epidemiol. 2015;182(7):644-50. doi:10.1093/aje/kwv101.

19. Kunzli N, Kaiser R, Medina S, Studnicka M, Chanel O, Filliger P, et al. Publichealth impact of outdoor and traffic-related air pollution: a European assessment. Lancet. 2000;356(9232):795-801.

20. Medina S, Plasencia A, Ballester F, Mucke HG, Schwartz J, Apheis Group. Apheis: public health impact of PM10 in 19 European cities. J Epidemiol Community Health. 2004;58(10):831-6. doi:10.1136/jech.2003.016386.

21. Ballester F, Medina S, Boldo E, Goodman P, Neuberger M, Iñiguez C, et al. Reducing ambient levels of fine particulates could substantially improve health: a mortality impact assessment for 26 European cities. J Epidemiol Community Health. 2008;62(2):98-105. doi:10.1136/jech.2007.059857.

22. Li Y, MacDonald Gibson J, Jat P, Puggioni P, Hasan M, West JJ, et al. Burden of disease attributed to anthropogenic air pollution in the United Arab Emirates: estimates based on observed air quality data. Sci Total Environ. 2010;408(23):5784-93. doi:10.1016/j.scitotenv.2010.08.017.

23. Baccini M, Biggeri A, Grillo P, Consonni D, Bertazzi PA. Health impact assessment of fine particles pollution at the regional level. Am J Epidemiol. 2011:174(12):1396-405. doi:10.1093/aje/kwr256.

24. Baccini M, Biggeri A. Short-term impact of air pollution among Italian cities covered by the EpiAir2 Project [Article in Italian]. Epidemiol Prev. 2013;37(45):252-62.

25. European Environment Agency. Spatial assessment of PM10 and ozone concentrations in Europe (2005. Copenhagen: European Environment Agency; 2009. doi:10.2800/165. Accessed 02 May 2016.

26. European Environment Agency. Air quality in Europe - 2014 report Luxembourg: European Environment Agency; 2014. doi:10.2800/22847. Accessed 02 May 2016.

27. Baccini M, Grisotto L, Catelan D, Consonni D, Bertazzi PA, Biggeri A. Commuting-adjusted short-term health impact assessment of airborne fine particles with uncertainty quantification via Monte Carlo simulation. Environ Health Perspect. 2015;123(1):27-33. doi:10.1289/ehp.1408218.

28. Berman JD, Fann N, Hollingsworth JW, Pinkerton KE, Rom WN, Szema AM, et al. Health benefits from large-scale ozone reduction in the United States. Environ Health Perspect. 2012;120(10):1404-10. doi:10.1289/ehp.1104851.

29. Heal MR, Heaviside C, Doherty RM, Vieno M, Stevenson DS, Vardoulakis S. Health burdens of surface ozone in the UK for a range of future scenarios. Environ Int. 2013;61:36-44. doi:10.1016/j.envint.2013.09.010.

30. Bonafè $G$, Stortini M, Minguzzi E, Deserti M. Postprocessing of a CTM with observed data: Downscaling, unbiasing and estimation of the subgrid scale pollution variability. In: Syrakos A, Bartzis JG, Andronopoulos S, editors. Proceedings of the 14th International Conference on Harmonisation within Atmospheric Dispersion Modelling for Regulatory Purposes. 2011. p. 302-6. paper: http://goo.gl/o8je4 poster:http://goo.gl/4FjbM. Accessed 02 May 2016.

31. Gandini M, Berti G, Cattani G, Faustini A Scarinzi C, De'donato F, et al. Environmental indicators in EpiAir2 project: air quality data for 
epidemiological surveillance [Article in Italian]. Epidemiol Prev. 2013;37(4-5): 209-19.

32. Environmental Systems Resources Institute ArcGIS Desktop 10.1. ESRI, Redlands; 2013.

33. Lu Y, Zeger SL. On the equivalence of case-crossover and time series methods in environmental epidemiology. Biostatistics. 2007;8(2):337-44. doi: 10.1093/biostatistics/kxl013.

34. R Core Team R. A language and environment for statistical computing. Vienna: R Foundation for Statistical Computing; 2014. http://www.r-project. org. Accessed 02 May 2016.

35. Sutton AJ, Abrams KR. Bayesian methods in meta-analysis and evidence synthesis. Stat Methods Med Res. 2001;10(4):277-303.

36. Lunn DJ, Thomas A, Best N, Spiegelhalter D. WinBUGS - A bayesian modelling framework: concepts, structure, and extensibility. Stat Comput. 2000;10(4):325-37.

37. Efron B, Morris C. Stein's paradox in statistics. Sci Am. 1977;236(5):119-27. doi:10.1038/scientificamerican0577-119.

38. Sterne JA, Davey Smith G. Sifting the evidence-what's wrong with significance test? BMJ. 2001;322:226-31.

39. Louis TA, Zeger SL. Effective communication of standard errors and confidence interval. Biostatistics. 2009;10:1-2.

40. Steenland K, Armstrong B. An overview of methods for calculating the burden of disease due to specific risk factors. Epidemiology. 2006;17(5):512-9.

41. Wacholder $\mathrm{S}$. The impact of a prevention effort on the community. Epidemiology. 2005;16(1):1-3.

42. World Health Organization. Air quality guidelines: global update 2005. Particulate matter, ozone, nitrogen dioxide and sulfur dioxide. Geneva: World Health Organization; 2005. http://whqlibdoc.who.int/hq/2006/WHO_ SDE_PHE_OEH_06.02_eng.pdf?ua=1. Accessed 02 May 2016.

43. European Commission. Directive 2008/50/EC of the European Parliament and of the Council of 21 May 2008 on ambient air quality and cleaner air for Europe. Offic J Eur Union 2008. http://eur-lex.europa.eu/LexUriServ/ LexUriServ.do?uri=OJ:L:2008:152:0001:0044:EN:PDF. Accessed 02 May 2016

44. Zeger SL, Thomas D, Dominici F, Samet JM, Schwartz J, Dockery D, et al. Exposure measurement error in time-series studies of air pollution: concepts and consequences. Environ Health Perspect. 2000;108(5):419-26.

45. Roemer WH, van Wijnen JH. Daily mortality and air pollution along busy streets in Amsterdam, 1987-1998. Epidemiology. 2001;12(6):649-53.

\section{Submit your next manuscript to BioMed Central and we will help you at every step:}

- We accept pre-submission inquiries

- Our selector tool helps you to find the most relevant journal

- We provide round the clock customer support

- Convenient online submission

- Thorough peer review

- Inclusion in PubMed and all major indexing services

- Maximum visibility for your research

Submit your manuscript at www.biomedcentral.com/submit
Biomed Central 